\title{
Serviço Social em Portugal
no fascismo: oposição,
resistência e ação sindical
}

Social Work in Portugal during fascism: opposition, resistance and union action

\begin{abstract}
Alcina Martins**
Resumo - Partilha-se a concepção de que o Serviço Social, enquanto profissão, é indissociável do desenvolvimento das relações sociais capitalistas, não se constituindo num bloco homogêneo. Na senda de Netto, os projectos societários em disputa pela manutenção ou transformação das estruturas sociais vigentes têm expressão nos projectos profissionais. Desse modo, com este trabalho procura-se contribuir para a análise da construção do Serviço Social em Portugal, apreendendo o significado atribuído pelo fascismo à profissão no processo de institucionalização, de 1930 a 1950. Pretende-se também identificar assistentes sociais ${ }^{1}$ que se foram envolvendo em movimentos de oposição e resistência ao regime e perceber como, nos anos 1960 e 1970, a profissão se foi distanciando do significado inicialmente atribuído, a partir da organização sindical corporativista.

Palavras-chave: fascismo; Portugal; oposição; resistência; Serviço Social; distanciamento; ação sindical; assistentes sociais.

Abstract - The concept of social work as a profession is inseparable from the development of capitalist social relations, and does not constitute a homogeneous bloc. According to Netto, the corporate projects in dispute for the maintenance or transformation of the existing social structures are expressed in professional projects. In this way, this work seeks to contribute to the analysis of the construction of social work in Portugal, grasping the meaning attributed by fascism to the profession in the process of institutionalization, from 1930 to 1950 . It is also intended to identify social workers ${ }^{2}$ who have been involved in movements of opposition and resis-
\end{abstract}

\footnotetext{
*Comunicação apresentada na Mesa Brasil e Portugal: regimes autocrático-burgueses e lutas sociais (19601980), no âmbito do Simpósio «Crise do capital e conflitos de classe no contexto mundial latino-americano (1960-1980)», realizado na Universidade Juiz de Fora, a 3 de novembro de 2016. Evento organizado e promovido pelo Grupo de Pesquisa "O Movimento de Reconceituação do Serviço Social na América Latina (Argentina, Brasil, Chile e Colômbia): determinantes históricos, interlocuções internacionais e memória". (1960-1980), coordenado pelas professoras Marilda V. Iamamoto (UERJ) e Cláudia Mônica dos Santos (UFJF) que integraram a comissão organizadora com a professora Alexandra Aparecida Eiras (UFJF), a quem renovo os meus agradecimentos pelo convite que me dirigiram.

** Doutorada em Serviço Social pela Pontifícia Universidade Católica de São Paulo. Professora associada e coordenadora do mestrado em Serviço Social do Instituto Superior Miguel Torga - Coimbra, Portugal. Correspondência: Instituto Superior Miguel Torga. Largo da Cruz de Celas, 1. 3000-132 Coimbra, Portugal. Email: <alcina55martins @gmail.com>.

1 Entrevistas realizadas pela autora a: Maria Eugénia Varela Gomes (26 de junho de 2000), Maria Gabriela Figueiredo Ferreira (15 e 22 de janeiro de 2001) e Maria Teresa Abrantes Pereira Ávila (20 de junho de 2000).

2 Interviews conducted by the author to: Maria Eugénia Varela Gomes (June 26, 2000), Maria Gabriela Figueiredo Ferreira (January 15 and 22, 2001) and Maria Teresa Abrantes Pereira Avila (June 20, 2000).
} 
tance to the regime and to perceive how, in the 1960s and 1970s, the profession was distanced of the initially attributed meaning, from the corporatist trade union organization.

Keywords: fascism in Portugal; opposition; resistance; social work; distancing; union action; social workers.

\section{Introdução}

Com este artigo procura-se contribuir para a análise da construção do Serviço Social em Portugal, apreendendo o significado atribuído pelo fascismo à profissão no processo de institucionalização, nos anos de 1930 a 1950. Pretende-se também identificar os assistentes sociais que se foram envolvendo em movimentos de oposição e resistência ao regime e, nos anos 1960 e 1970, como a profissão se foi distanciando do significado inicialmente atribuído a ela, a partir da organização sindical corporativista, tendo em vista que se partilha a concepção de que o Serviço Social, enquanto profissão, é indissociável do desenvolvimento das relações sociais capitalistas, não se constituindo num bloco homogêneo.

O artigo está estruturado em três pontos: no primeiro, faz-se uma abordagem do processo histórico, um breve apontamento quanto à natureza do regime em Portugal, que se autodenominou "Estado Novo", e a sua durabilidade, a mais longa ditadura da Europa. Segue-se uma referência aos últimos anos do fascismo, liderado por António Oliveira Salazar (1928-1968) e por Marcelo Caetano (1968-1974), anos de crise e declínio, de alargamento e de radicalização da oposição e resistência antifascista.

No terceiro ponto analisa-se como o regime concebeu o Serviço Social como uma finalidade da política social corporativa e as assistentes sociais como "cooperadoras da revolução nacional", além do modo como elas se foram distanciando, opondo e resistindo a tal entendimento. Para tanto, identifica-se a participação de assistentes sociais na oposição católica, as primeiras presas políticas, passando pelo envolvimento na oposição democrática, nos movimentos anticoloniais, até à ação sindical se constituir num campo de luta política para o Serviço Social.

\section{O fascismo e o corporativismo em Portugal}

Parte-se do entendimento de Fernando Rosas (2012), para quem o salazarismo constitui uma "modalidade específica" do fascismo, que participa do movimento particular do período entre guerras, em que o autori- 


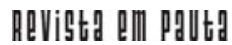

\} SERVICOO SOCIAL EM PORTUGAL NO FASCISMO - MARTINS, A. \}

DOI: $10.12957 /$ REP.2017.32722

tarismo procurou ser uma resposta política à industrialização, terceirização e urbanização, sendo uma tentativa de restauração da acumulação capitalista através da redução dos custos do trabalho.

Sendo o regime fascista português o que teve maior longevidade na Europa no século XX, Rosas (2012) analisa a longa duração do salazarismo como um fenômeno histórico em si, identificando cinco fatores estruturais da sua durabilidade: a violência (de tipo preventiva, intimidatória e desmobilizadora, e a de tipo repressiva, punitiva), o controle das Forças Armadas, a cumplicidade política e ideológica da hierarquia da Igreja Católica, a organização corporativa e o projeto totalitário do regime, com o "investimento totalitário no 'homem novo' salazarista" (ROSAS, 2012, p. 186-188). Nas palavras do autor:

O corporativismo é o fascismo enquanto regime. [...] participa da tarefa histórica nas economias periféricas: sujeitar o trabalho ao capital (dependendo das realidades nacionais, através de uma combinatória de violência, demagogia obreirista ou paternalismo social) e realizar a gestão autoritária e dirigista da economia no interesse da restauração da acumulação das classes dominantes e da perpetuação do seu domínio, erigindo essa «Nova Ordem» em 'Interesse Nacional'. (ROSAS, 2012, p. 313).

O corporativismo como pilar desta ordem se traduzirá num instrumento prático central da eficácia do fascismo português, com uma

dupla função de, por um lado, 'disciplinar' o trabalho, permitindo, sobre a negação dos seus direitos e a redução dos seus custos salariais, elevadas taxas de acumulação; por outro lado, regular autoritariamente a economia, protegendo mercados, garantindo privilégios, regulando a concorrência, assegurando folgadas taxas de lucro e de auto financiamento. (ROSAS, 2012, p. 355).

Ao condenar o sindicalismo, cuja liberdade de associação e de expressão foi arduamente conquistada desde os anos 1870, que apesar das perseguições e condicionamentos era livre, o regime fascista põe termo, pela repressão, à hegemonia anarco-sindicalista do movimento operário sindical português, evidenciado a partir dos primeiros anos da implantação da I República (1910). Proíbe, ainda, a Confederação Geral do Trabalho (CGT), a União Anarquista Portuguesa e as greves, interdita os partidos políticos, nomeadamente o Partido Comunista Português (PCP), que entra na clandestinidade, persegue democratas e enceta uma dura repressão à insurreição dos trabalhadores da Marinha Grande (1934) (NETTO, 1986; HENRÍQUEZ, 2001).

Como refere Rosas (2012), quebrar a espinha do movimento operário sindical e politicamente organizado era um dos objetivos essenciais do projeto corporativo. A política social no salazarismo não terá lugar fora desse projeto, quer em relação à assistência, quer ao nível da previdência 


\section{ReVistg all pantg}

\} SERVIÇO SOCIAL EM PORTUGAL NO FASCISMO - MARTINS, A. \}

DOI: $10.12957 /$ REP.2017.32722

social. O sistema de previdência social contempla algumas franjas de trabaIhadores, mas a maioria não será abrangida (HENRÍQUEZ, 1998).

O regime contará com outro pilar, a saber, a cumplicidade política e ideológica da hierarquia da Igreja Católica. Segundo António Barreto (2000, p. 375),

[...] nunca a Igreja Ihe faltou com o seu apoio explícito: na fundação do regime, na limitação das liberdades públicas, na criação da censura, no estabelecimento do sistema corporativo, na elaboração da Constituição, durante a guerra, no combate ao comunismo internacional, na resistência à descolonização e na condução da guerra colonial, sempre a Igreja partilhou com ele as principais decisões e os desígnios essenciais. Não era a Igreja que influenciava o poder, era Salazar que, em boa medida, a submetia.

Mas o Estado Novo não foi, em nenhum dos seus momentos, inelutável. A história da oposição e resistência antifascista, nas suas diferentes vertentes, é disso expressão.

Com a ascensão dos regimes fascistas e nazistas na Europa, dos anos 1930 até ao fim da Segunda Guerra Mundial, tem lugar em Portugal: a derrota e a rendição do reviralhismo republicano, a resistência políticomilitar dos setores do republicanismo, que não tinham capitulado perante a ditadura militar e a consolidação do novo regime, o colapso do movimento libertário e a organização do PCP, que, após a reorganização de 1940/ 1943, constitui-se num forte partido clandestino, com influência nacional nas concentrações operárias, entre assalariados rurais do sul, junto da juventude estudantil e na intelectualidade (ROSAS, 2004).

Por outro lado, em 1945, é criado o Movimento de Unidade Democrática (MUD), ilegalizado passados três anos. Em 1949, o movimento apoia a candidatura da oposição do general Norton de Matos às eleições presidenciais. À derrota da oposição segue-se uma década de refluxo e desmobilização face ao anticomunismo reinante.

A "unidade", em meio às diversas correntes oposicionistas, entre 1956 e 1968, será instável, quase sempre pontual, marcada por desconfianças. Além disso, os momentos unitários com expressão pública serão quase sempre hegemonizados política e ideologicamente pela oposição não comunista. A candidatura em 1958 do general Humberto Delgado às eleições presidenciais insere-se neste processo.

A resistência democrática consegue a mobilização e a participação popular em grandes manifestações, provocando um abalo ao regime. Diante da pergunta acerca de que posição tomaria perante Salazar, Delgado responde: "obviamente, demito-o", o que foi uma declaração de guerra ao regime. Vítima da fraude eleitoral e de represálias pela Polícia Internacional e de Defesa do Estado (PIDE), em 1959 Delgado pediu asilo político na Embaixada do Brasil, seguindo depois para o exílio na Argélia. Convencido de 


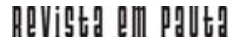

\} SERVIÇO SOCIAL EM PORTUGAL NO FASCISMO - MARTINS, A. \}

DOI: $10.12957 /$ REP.2017.32722

que o regime não poderia ser derrubado pelos meios pacíficos, atrai chefias militares para um golpe de Estado, tomando de assalto, em 1962, o Quartel de Beja.

A oposição católica emerge durante a campanha. No rescaldo das eleições presidenciais de 1958, protesta contra a sua parcialidade, por favorecer o candidato do governo e pelo cercear da liberdade dos movimentos católicos. Diante desse contexto, o próprio Bispo do Porto passa a distanciar-se da identificação da Igreja com o regime.

\section{Crise e declínio do regime: a oposição e a resistência}

O rescaldo de 1958 e os primeiros anos de 1960 são de sobressalto para o regime: a fuga de Álvaro Cunhal e outros militantes do $\mathrm{PCP}$, a prisão de Peniche (1960), o assalto ao paquete "Santa Maria" (1961) por Henrique Galvão, a tentativa de golpe palaciano de Botelho Moniz e a Crise Acadêmica de 1962, que marca a resistência estudantil e as jornadas de luta pelas oito horas de trabalho no Alentejo. Além disso, a união indiana ocupa os então territórios portugueses de Goa, Damão e Diu, pondo fim ao Estado Português na Índia; tem início a guerra colonial em Angola (1961), na Guiné (1963), e em Moçambique (1964), além do isolamento externo do governo português na ONU.

A partir dos anos 1960, o regime entrará em crise e declínio. Contribuem para tal "a guerra colonial e a crise económica - de que emergem, pela mediação da resistência democrática, o isolamento internacional e nacional do fascismo. [...] A luta da oposição democrática impede que o regime se recompusesse com uma alternativa de sobrevivência" (NETTO, 1986 , p. 29, p. 35).

O marcelismo nos primeiros anos (1968-1970) esboça algumas medidas liberalizantes e uma relativa abertura política, a chamada "primavera marcelista", mas que acaba por ser uma "renovação na continuidade" do salazarismo. A mudança cosmética de nomes da polícia política, do partido da União Nacional e das "províncias ultramarinas", que passam a designar-se "estados", não resolverá as questões com que o regime se vinha confrontando. A não resolução da questão da guerra colonial compromete a tentativa do regime de se autorreformar.

A estrutura social alterou-se. Se em 1960 a população ativa encontrava-se majoritariamente na agricultura (43\%), em 1970 esse número diminui, em grande medida, devido à emigração. Mais de um milhão de portugueses foge à pobreza e às más condições de vida e de trabalho, à guerra e ao atraso do país. Cresce o número de trabalhadores nos setores secundário e terciário. Neste último, emergem novos profissionais, técnicos e funcionários públicos qualificados. As suas aspirações colidem "com os constrangimentos económicos, sociais e culturais da politica do regime fas-

EM PAUTA, Rio de Janeiro - 20 Semestre de 2017 - n. 40, v. 15, p. 40 - 56 


\section{ReVistg all pantg}

\} SERVIÇO SOCIAL EM PORTUGAL NO FASCISMO - MARTINS, A. \}

DOI: $10.12957 /$ REP.2017.32722

cista, e suas expectativas frustadas vão fazer com que boa parte deles aflua a fileiras da oposição democrática" (NETTO, 1986, p. 33).

O movimento sindical aproveitará a "abertura sindical" de 19691970 com a "abolição do sancionamento governamental dos dirigentes eleitos e, no plano da contratação colectiva, a consagração da obrigatoriedade de negociar e o consequente estabelecimento de mecanismos de resolução dos conflitos colectivos de trabalho" (BARRETO, 1990, p. 58; MARTINS, 2003). Este reforço da ação sindical faz-se também com os trabalhadores dos serviços. O movimento estudantil, alvo de forte repressão, e a recusa da mobilização dos jovens para a guerra, trazem novas configurações à resistência ao fascismo.

As ilusões frustradas da mudança de regime contribuem para a "radicalização decisiva das posições e da intervenção de todo o espectro das oposições ao regime, como instalarão uma agitação na oficialidade intermédia, cansada da guerra, que virá a ser fatal" (ROSAS, 2004, p. 117). A partir de 1970 surgem grupos marxistas-leninistas, maoístas e trotskistas, com intervenções no meio estudantil, colocando no centro da luta política a questão do colonialismo e a luta contra a guerra colonial. Neste processo de radicalização, o contexto internacional traz contribuições, com as revoltas estudantis na França, Alemanha e Itália, em 1968-1969, com a denúncia internacional da Guerra do Vietnã, com o diferendo nas relações sinosoviéticas, com a Revolução Cultural da China, com a invasão da Tchecoslováquia (1968) e com os movimentos de libertação nacional.

A oposição católica vem também a radicalizar-se. Os "católicos progressistas", inspirados em leituras do Concílio do Vaticano Il e da Teologia da Libertação, centram-se agora no combate social e político, criando vários núcleos clandestinos e de agitação anticolonialista. Publicações como Direito à informação, o Grupo de estudos e intercâmbios de documentos, informações e experiências (Gedoc), fazem a denúncia da guerra colonial e da colaboração da hierarquia da Igreja católica com o regime e com o conflito nas colônias. Alguns destes grupos chegam a dar apoio logístico a organizações de luta armada na fase final do regime.

Atentados bombistas são suscitados por várias organizações, como as Brigadas Revolucionárias, que lutavam contra as instalações da Nato na Fonte da Telha e instalações militares, desencadeando ações de propagada com recurso a petardos e apoio à Vigília Anticolonial na Capela do Rato, com conexões aos católicos progressistas.

Para a radicalização política e bombista anticolonial contribuirá a conspiração dos oficiais, na frente da Guiné, que leva ao "movimento de capitães". Inicialmente, contestam legislação contrária à progressão na carreira, mas vêm a transformar-se no Movimento das Forças Armadas, que derruba o regime no dia 25 de abril de 1974.

O corporativismo salazarista e marcelista deixará "um país atrasado, com o menor rendimento por habitante da Europa, a maior taxa de 


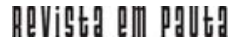

\} SERVICOO SOCIAL EM PORTUGAL NO FASCISMO - MARTINS, A. \}

DOI: $10.12957 /$ REP.2017.32722

analfabetismo, a pior cobertura do sistema de saúde ou de segurança social e a maior concentração de população na agricultura" (LOUÇÃ; LOPES; COSTA, 2014, p. 21). Por outras palavras, "uma ditadura paralisada, uma guerra sem solução, uma economia em crise. Metade da riqueza nacional estaria nas mãos de dez famílias, donas das 168 maiores empresas" (COSTA et al., 2010, p. 250).

Ora, é o Movimento das Forças Armadas que vai fazer depor o governo. Juntamente com o povo, enchem as ruas de Lisboa e do país, colocando cravos nas armas dos soldados. Desse modo, transformam o golpe militar num processo revolucionário, a denominada Revolução dos Cravos. Na voz do poeta Ary dos Santos, "ninguém mais cerra as portas que Abril abriu!".

O processo revolucionário faz a ruptura com a ditadura, de modo que são libertados os presos políticos, pondo termo à censura, à polícia política e às estruturas da ditadura, mudando radicalmente a sociedade portuguesa. Terminam treze anos da guerra colonial, as colônias africanas tornam-se independentes, bancos são nacionalizados e a reforma agrária tem lugar no Alentejo. Agora, as lutas são pelo trabalho para todos, pelo aumento dos salários e pelo direito à segurança social, habitação, saúde e educação (VARELA, 2014).

\section{Significado atribuído ao Serviço Social e o distanciamento, oposição e resistência de assistentes sociais}

O regime, ao equacionar uma resposta corporativista à questão social de feição caritativa, assistencial e de previdência social, vai configurar o Serviço Social como um agente dessa construção, ao serviço da ação de propaganda e doutrinamento dos valores do "Estado Novo". Assim, contribui para neutralizar tentativas de agitação social ou revolta, por parte dos trabalhadores e dos mais pobres (MARTINS, 2009).

É no $1^{\text {o }}$ Congresso do Partido Único, a União Nacional (1934), que é proposta a criação de escolas de Serviço Social. Em 1935, o Patriarcado de Lisboa, por intermédio de uma associação de beneficência, a Associação de Serviço Social, cria o Instituto de Serviço Social em Lisboa (ISSL). Em 1937, um organismo de administração pública de âmbito regional, a Junta da Província da Beira Litoral, cria, em Coimbra, a Escola Normal Social, com a mediação de uma congregação, as Franciscanas Missionárias de Maria. Esta escola designa-se atualmente como Instituto Superior Miguel Torga.

O Estado vem, em 1939, a oficializar estas escolas, estabelecendo os princípios gerais de orientação a que hão-de submeter-se. É concedido o diploma do curso e o título de assistente de Serviço Social ao plano geral de estudos aprovados, "tudo para a formação de dirigentes idóneas e responsáveis no meio a que se destinam, ao mesmo tempo conscientes e activas 


\section{ReVistg all pantg}

\} SERVIÇO SOCIAL EM PORTUGAL NO FASCISMO - MARTINS, A. \}

DOI: $10.12957 /$ REP.2017.32722

cooperadoras da Revolução Nacional [...] para que jamais possa desviar-se do sentido humano corporativo e cristão" (Decreto-Lei no 30135, de 14 de Dezembro de 1939).

O corporativismo, apresentado como uma terceira via, alternativa ao liberalismo e ao socialismo, asseguraria a colaboração entre as classes sociais e grupos de interesse, através da harmonização e da concertação no seio das corporações (MARTINS, 2010).

O Serviço Social inscreve-se nesses desígnios, vindo o Estado a realçar a intervenção das "obreiras do Serviço Social" junto de "famílias de todas as condições", mas sobretudo de "famílias humildes e de restrita cultura, as mais facilmente influenciáveis", em "fábricas, organizações profissionais, instituições de assistência e de educação colectiva e de obras similares", com "múltiplos objectivos - higiénicos, morais e intelectuais" (Decreto-Lei no 30135, de 14 de Dezembro de 1939).

Fomentar o espírito de cooperação entre trabalhadores e patrões e negar o conflito de classes era o que se esperava do trabalho da assistente social. A assistência deve ser corporativa e, nas palavras de Oliveira Salazar,

deve ter origem e fim no seio da família, salvo nos casos de manifesta impossibilidade. Os pais mandam os filhos para as creches e asilos; os filhos internam os pais; e os irmãos dividem-se por sanatórios e casas de saúde [...] isto é comunismo puro, porque atenta directa e gravemente contra os alicerces da família, provocando a sua dissolução. (MARTINS, 2010, p. 262-263).

Neste sentido, Adérito Sedas Nunes (1955, p. 343) afirmava, na Revista do Gabinete de Estudos Corporativos, fonte doutrinária do corporativismo, que

a realização das formas sociais preconizadas pelo pensamento corporativo aparece formalmente condicionada por acções do Serviço Social [...] e o desenvolvimento do Serviço Social deve ser actualmente considerado uma finalidade direta, de primeiro plano, da Política Social.

Entre os objetivos do Serviço Social, o autor apontava o "aproximar as várias classes sociais numa acção de conjunto (por exemplo, no seio das empresas, através das 'obras sociais'), e, por essa via, combater o espírito de luta de classes, existente ou em formação" (NUNES, 1955, p. 161).

A perspetiva antiliberal de feição corporativista negará a autonomia individual, exigindo a subordinação absoluta à coletividade, aos grupos e às associações intermediárias, como sejam a família, a Igreja e as corporações (MARTINS, 2010). O corporativismo português é estatista, católico e conservador. Conservadorismo que enaltece os valores da tradição, da ordem e da estabilidade, com tradução na divisa "Deus, Pátria e Família", atravessado pela noção cristã da chefia e da obediência, da humildade e da pobreza, da negação das inovações e pelo ideal neotomista de uma paz assentada numa 


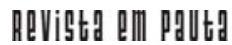

\} SERVIÇO SOCIAL EM PORTUGAL NO FASCISMO - MARTINS, A. \}

DOI: $10.12957 /$ REP.2017.32722

sociedade rural e tradicionalista, anti-industrial e contrária à luta de classes (MEDINA, 2000). Tem, na Ciência Social de Fréderic Le Play e dos seus continuadores, outra das suas fontes (MARTINS, 2010).

À formação em Serviço Social subjaz o doutrinarismo, alicerçado nos valores da "educação da família", a "recristianização da sociedade" e os valores nacionalistas e corporativistas, imbuídos do pensamento conservador, que expressam os desígnios do regime e da Doutrina Social da Igreja.

A institucionalização do Serviço Social nesta conjuntura sociopolítica ocorre também com a criação do mercado de trabalho para assistentes sociais ao nível dos serviços públicos de assistência, hospitais, dispensários, organizações femininas do regime, Juntas de Província e serviços do Ministério das Corporações. Organizações privadas, empresariais e assistenciais vão também recrutar estes profissionais.

A intervenção política de assistentes sociais no salazarismo tem lugar na Assembleia Nacional, a partir de 1949, como deputadas da União Nacional, da Acção Nacional Popular (ANP) e da sua Ala Liberal, depois de 1970. Até à queda do regime serão cinco as deputadas assistentes sociais. Pertencem a organizações do regime (Obra das Mães pela Educação Nacional, Instituto de Assistência à Família), da Igreja (União Noelista Portuguesa, Movimento Diocesano das Assembleias Familiares, Conferências Vicentinas) e a organizações internacionais de Serviço Social (União Católica Internacional de Serviço Social "Uciss " e, nos anos 1970, Comissão Portuguesa do Conselho Internacional do Serviço Social " CPCISS) (RODRIGUES, 2014).

Quando cerca de 150 assistentes sociais se formam, é criado, em 1950, o Sindicato Nacional das Assistentes Sociais, Educadoras Familiares e outras Profissionais do Serviço Social. Um terço delas sindicaliza-se. Tratase de um organismo corporativo, à semelhança dos restantes sindicatos nacionais, dependente do Ministério das Corporações e Previdência Social, que aprova os estatutos cujo articulado o faz "renunciar a toda e qualquer forma de actividade, interna ou externa, contrária aos interesses da Nação Portuguesa [...], subordina os seus interesses ao interesse superior da economia nacional" e "repudia a luta de classes" (MARTINS, 2003, p. 55).

Vem, em 1951, a filiar-se à Uciss, seguindo as suas orientações, promovendo retiros espirituais, organizando ações de aperfeiçoamento profissional e publicando a revista Cadernos de Serviço Social, não se conhecendo qualquer iniciativa em prol da melhoria das condições salariais e de trabalho das suas associadas ou de outros trabalhadores (MARTINS, 2003).

Até aos anos 1950, o Serviço Social não se distanciava da legitimidade conferida pelo regime, salvo raras exceções. Eis o testemunho de uma assistente social que trabalhava nos bairros sociais de Lisboa, revoltada e indignada com a situação.

Pediam-nos dinheiro, o dinheiro não chegava ao fim do mês, não tinham para pagar a renda de casa, era uma miséria completa. Cada vez que havia manifestações do Governo ao Salazar, as carrinhas da polícia iam

EM PAUTA, Rio de Janeiro - 20 Semestre de 2017 - n. 40, v. 15, p. 40 - 56 
ao bairro, arrebanhavam aquela gente toda e traziam-na para a manifestação. Naquele tempo, o sangue não se oferecia, vendia-se e era assim que a maioria daquelas famílias pagavam as rendas de casa. Não adiantava nada andarmos a resolver os problemas desta ou daquela família. A minha revolta era tão grande que disse, 'não volto a trabalhar como assistente social. Não queria continuar cúmplice do sistema, nem ser conivente com os exploradores do meu país e seus governantes'. Ser 'a gota de óleo', qual gota de óleo, não temos nada que ser gota de óleo, pelo contrário. (Entrevista da autora a Maria Eugénia Varela Gomes, 2000).

\section{Oposição democrática e as primeiras presas políticas}

A intervenção política de assistentes sociais na oposição democrática ao regime terá lugar a partir do final dos anos 1950, associada às campanhas para as eleições presidenciais (1958) e legislativas (1961). Uma assistente social que não esconde ser apoiante de Humberto Delgado, por ação dos informadores, acaba por ser suspensa do Hospital de Santa Maria, onde trabalhava por seis meses, sendo-lhe instaurado um processo disciplinar.

No processo de radicalização da luta contra o regime, com a Revolta da Sé (1959) e na tentativa revolucionária do assalto ao Quartel de Beja (1962), que "polarizam para a luta armada sectores que se vinham perfilando nas fileiras oposicionistas, em larga medida à margem da tutela e da influência do Partido Comunista" (MADEIRA, 2002, p. 23), encontramos assistentes sociais que virão a ser as primeiras presas políticas.

Na sequência da tentativa de derrubada do regime por golpe militar, com o assalto ao Quartel de Beja, sob acusação "de alteração da Constituição, por rebelião à mão armada", Maria Eugénia Varela Gomes é julgada e condenada a 17 meses, com suspensão de direitos políticos por cinco anos, como consta da biografia prisional do processo da PIDE (Torre do Tombo, Fundo PIDE/DGS. Ela se torna a primeira assistente social presa política, sujeita à tortura.

Mesmo após a sua libertação, foi sempre vigiada pela polícia política, tendo correspondência interceptada e a casa sendo alvo de buscas. Em 1969, o então Diretor da Direção Geral de Segurança (assim designada) "considerou inconveniente a sua readmissão no Hospital de Santa Maria 'por a interessada não oferecer garantias de cooperar com os fins superiores do Estado"” (PIMENTEL, 2007, p. 339).

A sua prisão desencadeia reações de várias ordens, dentro e fora da profissão. Em apoio e solidariedade internacional, corresponderá a condenação da sua ação pelo Sindicato Nacional das Assistentes Sociais, Educadoras Familiares. A direção do sindicato condena estes atos políticos e expulsa-a. 


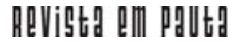

\} SERVIÇO SOCIAL EM PORTUGAL NO FASCISMO - MARTINS, A. \}

DOI: $10.12957 /$ REP.2017.32722

Além disso, a assistente social Maria Manuela Antunes foi praticamente raptada no Porto e trazida para a prisão de Caxias, saindo no mês seguinte, em 1962, por denúncia de ter escondido o dirigente da Revolta da Sé, Manuel Serra, dirigente da juventude operária católica, em casa do Padre Abel Varzim. Este padre, que inicialmente apoiou o corporativismo e dele se distanciou, caiu em desgraça política, sendo afastado das funções de deputado, na Acção Católica Portuguesa, e de professor do ISSL em 1949. O seu afastamento do Instituto vai desencadear, num pequeno grupo de alunas de Serviço Social, entre elas Eugénia Varela Gomes e Manuela Antunes, uma reação de inconformismo. Quando têm conhecimento de que ele deixara de ser professor no Instituto, elas vão, junto da Direcção do ISSL e do Patriarcado, exigir explicações e mostrar que não aceitavam a decisão tomada (Entrevista da autora a Maria Eugénia Varela Gomes, 2000).

Se até ao início dos anos 1960 contava-se pelos dedos de uma mão a participação de assistentes sociais em ações políticas de oposição e resistência, no final da década de 1960 e nos anos 1970 a tendência é a existência de uma adesão mais alargada, através de iniciativas dos católicos progressistas e da radicalização dos movimentos anticoloniais. No contexto da "primavera marcelista", destaca-se também a intervenção de assistentes sociais na oposição democrática, no movimento sindical crítico do corporativismo, estando subjacente um processo de politização com repercussão na configuração do projeto profissional, que se constituiu nestes anos até à queda do fascismo.

\section{Participação nas eleições pela oposição democrática}

A estratégia de alargamento das bases de apoio nas eleições de 1969 leva à aproximação do PCP aos católicos progressistas e independentes, sendo criado o movimento da Comissão Democrática Eleitoral (CDE). Organizações de base com funcionamento democrático disputaram lugares na quase totalidade dos círculos eleitorais. A CDE do Distrito de Lisboa apresentava delegados das Comissões concelhias, dos setores socioprofissionais, de mulheres, de estudantes, da Comissão Coordenadora e da Comissão Política. Nos períodos eleitorais (1969 e 1973), a CDE fará uma mobilização ao nível dos trabalhadores e das estruturas sindicais, constituindo as bases socioprofissionais.

Assistentes sociais integraram o movimento da CDE, quer ao nível da comissão política (assistente social Eugénia Pereira de Moura), quer das bases socioprofissionais, passando a intervir na atividade sindical e a integrar as direções do Sindicato Nacional dos Profissionais de Serviço Social (SNPSS). A alteração da designação do sindicato, em 1964, advém da frequência de homens no curso. As listas de candidatos da CDE às eleições em 1973 também contemplaram, no Porto, uma assistente social, associada ao mo- 


\section{ReVistg all pantg}

\} SERVIÇO SOCIAL EM PORTUGAL NO FASCISMO - MARTINS, A. \}

DOI: $10.12957 /$ REP.2017.32722

vimento de mulheres. Berta Granja, estudante do Instituto Superior de Serviço Social do Porto, que trabalhava em bairros operários da cidade na campanha eleitoral, teve intervenções que incidiram na situação das mulheres portuguesas e na guerra colonial (FERREIRA, 2003). Assistentes sociais envolveram-se na campanha eleitoral, quer em 1969, quer em 1973, por todo o país.

\section{Questão colonial, radicalização da resistência e envolvimento de assistentes sociais}

Estando a questão colonial no centro das preocupações da oposição, o envolvimento de alguns assistentes sociais manifestou-se: nas organizações e ações de resistência dos católicos progressistas contra a guerra colonial, em que se destacou a participação nas Cooperativas Culturais, como a "Pragma" e "Confronto". Estas cooperativas constituíram um recurso hábil para contornar as dificuldades jurídicas que a ditadura levantava ao livre exercício do direito de associação. Elas foram criadas em 1964, sendo promovidas por católicos ligados ao meio estudantil e operário que procuravam abrir o diálogo com diversos grupos sociais, contando com a participação de assistentes sociais em Lisboa e no Porto. Registrou-se também a sua participação nas Vigílias pela Paz, na Igreja de S. Domingos (1969) e na Capela do Rato (1972). Na vigília da Capela do Rato, em 1972, foi aprovada uma moção contra a política colonial, repudiando a empreitada belicista portuguesa, seguindo-se uma greve de fome, gesto de solidariedade para com as vítimas da guerra colonial e os povos em luta.

Assistentes sociais participaram ativamente da vigília de 1972, tendo o apoio do SNPSS. A repressão que se seguiu atingiu, entre muitos outros, duas assistentes sociais e a auxiliar social, que foram detidas e alvo de interrogatórios pela PIDE/DGS, processo disciplinar, e demitidas da administração pública: Maria Teresa Abrantes Pereira Ávila e Maria Gabriela Figueiredo Ferreira, bem como a auxiliar social Ludovina Esteves (ZENHA et al., 1973; MARTINS, 2003).

O SNPSS, nesta altura, contestará a situação em que se encontravam as suas associadas, fazendo diligências junto da polícia política, dos ministérios e da Assembleia Nacional. Na sequência deste processo, Maria Teresa Abrantes vê o seu pedido de bolsa ao Instituto de Alta Cultura ser recusado e sai do país, viajando para o Brasil a fim de frequentar o mestrado na Faculdade de Serviço Social da Pontifícia Universidade Católica de São Paulo (Entrevista da autora a Maria Teresa Abrantes Pereira Ávila, 2000.). Quando regressa a Portugal, contribui para a divulgação de autores do Movimento de Reconceitualização do Serviço Social latino-americano, sobretudo do Chile, Argentina, Uruguai e Brasil. Se os planos de estudo das escolas de Serviço Social do Chile e os livros destes autores escaparam às malhas 


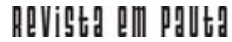

\} SERVIÇO SOCIAL EM PORTUGAL NO FASCISMO - MARTINS, A. \}

DOI: $10.12957 /$ REP.2017.32722

da censura, já o curso que o uruguaio Herman Kruse fará sobre este movimento, no país, em dezembro de 1973, ficará sob a vigilância da polícia política.

Assistentes sociais também se envolveram na edição de publicações legais e clandestinas (Cadernos do diálogo e Gedoc, no Centro de Informação e Documentação Amílcar Cabral - Cidac ", vindo a integrar o grupo de católicos que publicava o Boletim anti-colonial - BAC). Em dezembro de 1973, todo o grupo que editava o BAC é preso, incluindo a assistente social Maria Gabriela Ferreira. Presa em Caxias durante cerca de três meses, sairá em fevereiro de 1974, para aguardar julgamento em liberdade (Entrevista da autora a Maria Gabriela Figueiredo Ferreira, 2001).

As assistentes sociais presas políticas envolveram-se em organizações de solidariedade para com os presos políticos, desde início, no executivo da organização unitária, que integra católicos, comunistas, socialistas e a Comissão Nacional de Socorro aos Presos Políticos (CNSPP), criada em finais de 1969. Desenvolveram um significativo trabalho, em prol da denúncia da repressão, tortura, violação dos direitos e liberdades e de situações de injustiça, pela melhoria das condições de vida dos presos e suas famílias, quer ao nível nacional, quer internacional. Organização que deu continuidade ao trabalho político, clandestino, iniciado no início dos anos 1960, numa das células, em Portugal, da Frente Patriótica de Libertação Nacional, a que esteve associada Eugénia Varela Gomes.

\section{A ação sindical: um campo de luta política para o Serviço Social de crítica ao corporativismo}

Assistentes sociais que trabalhavam em grandes empresas e ativistas nas bases socioprofissionais da CDE serão dirigentes do SNPSS (Maria Teresa Serôdio Rosa, Dinah Ferreira). Isso ocorreu com a "abertura sindical", quando as direções "progressistas" do SNPSS, de 1970 a 1974, integravam ou foram constituídas por assistentes sociais, que se apresentavam como independentes do poder vigente, sobretudo após a adesão do SNPSS às reuniões intersindicais, base da Intersindical Nacional, criada em 1970 (a atual Confederação Geral dos Trabalhadores Portugueses "Intersindical Nacional CGTP). Esta participação exigiu-Ihes um posicionamento político.

Em Assembleia Geral do Sindicato é colocada e debatida a seguinte questão: "queremos estar ao lado dos trabalhadores ou queremos estar ao lado dos patrões e do governo?" (Entrevista da autora a Maria Teresa Abrantes Pereira Ávila, 2000). Com posições extremadas, a resposta foi ficar ao lado dos trabalhadores. Esta participação vem reforçar a ação pioneira do sindicato no campo da negociação coletiva de acordos de empresa ou contratos coletivos de trabalho, nas empresas com assistentes sociais, e na definição das funções da Administração Pública, com incidência na classificação na grelha salarial, autonomia e relações com a hierarquia. 


\section{heVistg all pgutg}

\} SERVIÇO SOCIAL EM PORTUGAL NO FASCISMO - MARTINS, A. \}

DOI: $10.12957 /$ REP.2017.32722

A intervenção sindical torna-se um campo de luta política das assistentes sociais pela liberdade sindical, mesmo quando proibidas as reuniões intersindicais, que continuaram a realizar-se na semiclandestinidade. Assim, desenvolve alianças e cumplicidades com as lutas dos trabalhadores, rompendo com o isolamento e ultrapassando o medo, manifestando solidariedade e exigindo justiça para com assistentes sociais presas, perseguidas e alvo da repressão.

A existência de projetos profissionais em disputa, com diferenças teóricas e políticas no Serviço Social, tem expressão em 1973, com a apresentação de duas listas às eleições para o sindicato. Vence a defesa pela vanguarda das assistentes sociais, que considerava que os profissionais de Serviço Social "exercem a sua actividade no âmbito das relações sociais em ordem à resolução dos problemas que surgem nessas relações, através da prestação directa, planeamento e administração de serviços sociais, participação na definição da política social, ensino e investigação" (SNPSS, 1971).

\section{Considerações finais}

Assistentes sociais, através do seu envolvimento em organizações associadas aos católicos progressistas, ações políticas de oposição e resistência, e sobretudo a partir da organização coletiva sindical dos últimos anos de 1960 e primeiros de 1970, distanciaram-se da legitimidade atribuída pelo fascismo, afirmando o Serviço Social como profissão. Desse modo, os profissionais reconheceram a sua condição de assalariados, aliando-se à luta dos trabalhadores. Segundo Maria Teresa Serôdio Rosa (1997, p. 3031), presidente do SNPSS (1969-1972),

o contacto com outros Sindicatos - de que à partida se estava afastado, por imposição legal, mas que a negociação colectiva acabou por aproximar - permitiu tomar-se conhecimento directo das limitações do associativismo, impostas pelo regime totalitário e consolidou um sentimento de revolta e uma opção de solidariedade com os outros trabalhadores na luta contra esse regime. [...] sentiam-se conscientes da sua condição de assalariadas submetidas, mas com algum poder (o que decorre da associação com os outros trabalhadores assalariados, independentemente do seu estatuto social) e que buscavam negociar as suas condições de trabalho e do exercício profissional.

Parafraseando César de Oliveira (2000, p. 434), se os sindicatos passaram a constituir-se "como um instrumento que a ditadura e o regime não podiam dominar e que serviu à causa da luta pela democracia", o SNPSS inseriu-se nos últimos anos nessa estratégia de resistência ao fascismo, em prol de uma sociedade democrática e de um novo significado social para o Serviço Social. Estas vanguardas, que nestes anos encetaram um percurso tendente a constituírem-se num sujeito profissional, com a Revolução de 


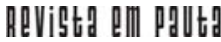

\{ SERVIÇO SOCIAL EM PORTUGAL NO FASCISMO - MARTINS, A. \}

DOI: 10.12957/REP.2017.32722

Abril de 1974, vão envolver-se em ações e lutas coletivas em prol de uma sociedade socialista. 


\section{heVistg all pavtg}

\} SERVIÇO SOCIAL EM PORTUGAL NO FASCISMO - MARTINS, A. \}

DOI: $10.12957 /$ REP.2017.32722

\section{Referências}

ARQUIVO PIDE/DGS. Biografia prisional de Maria Eugénia Bilnstein de Menezes Luís de Sequeira Varela Gomes. SC/Doc. RGP no 24896. Lisboa: Arquivo Nacional Torre do Tombo.

BARRETO, A. Salazar, António de Oliveira - o após-guerra. In: BARRETO, A.; MÓNICA, F. (Coord.). Dicionário de História de Portugal. Vol. 9. Lisboa: Livraria Figueirinhas, 2000.

BARRETO, J. Os primórdios da Intersindical sob Marcelo Caetano. Análise Social, Lisboa, n. 105-106, 1990.

COSTA, J. et al. Os donos de Portugal. Cem anos de poder económico (19102010). Porto: Edições Afrontamento, 2010.

FERREIRA, A. M. O discurso da resistência ou a resistência do discurso. Os assistentes sociais de oposição ao Estado Novo (1969-1973). Dissertação (Mestrado de Serviço Social, Instituto Superior de Serviço Social de Lisboa, Lisboa, 2003 (mimeo).

HENRÍQUEZ, B. A. O estado de mal-estar social salazarista e a política social do Estado Novo. Intervenção Social, Lisboa, n. 23/24, 2001.

. A construção do Serviço Social português e o Estado de mal-estarsalazarista. Dissertação (Mestrado de Serviço Social), Instituto Superior de Serviço Social de Lisboa, Lisboa, 1998 (mimeo).

LOUÇÃ, F.; LOPES, J. T.; COSTA, J. Os burgueses. Quem são, como vivem e como mandam. Lisboa: Bertrand Editora, 2014

MADEIRA, J. Entrevista de Manuel Serra a João Madeira. História, Lisboa, n. 43, 2002.

MARTINS, A. Investigação em Serviço Social: perspectivas actuais. In: HENRÍQUEZ, B. A.; FARINHA, M. A. (Org.). Serviço Social: unidade na diversidade. Encontro com a Identidade Profissional. In: I CONGRESSO NACIONAL DE SERVIÇO SOCIAL, Lisboa, Associação dos Profissionais de Serviço Social, 2003.

. 70 anos de formação em Serviço Social em Tempos de Ditadura e de Democracia: da Escola Normal Social ao Instituto Superior Miguel Torga. Revista Temporalis, Brasília, ano 9, n. 18, 2009.

. Génese, emergência e institucionalização do Serviço Social português. Beja Local: Encadernação Progresso, 2010.

MEDINA, J. Ideologia e mentalidade do "Estado Novo" salazarista. In: História do pensamento filosófico português. Vol. $\mathrm{V}$ - O século XX, tomo 2. Lisboa: Editorial Caminho, 2000.

NETTO, J. P. Portugal. Do fascismo à revolução. Porto Alegre: Mercado Aberto, 1986. 
NETTO, J. P. A construção do projeto ético-político do Serviço Social frente à crise contemporânea. In: Serviço Social, ética e deontologia e projetos profissionais. Lisboa/Madrid/São Paulo: CPIHTS/ICSA/Veras, 2001.

NUNES, A. S. A organização corporativa e o Serviço Social. Revista do Gabinete de Estudos Corporativos, Lisboa, n. 22/n. 24, 1955.

OLIVEIRA, C. Sindicalismo. In: BARRETO, A; MÓNICA, F. (Coord.). Dicionário de História de Portugal. Vol. 9. Lisboa: Livraria Figueirinhas, 2000.

PIMENTEL, I. F. A História da PIDE. Rio de Mouro: Círculo de Leitores, Temas e Debates e autora, 2007.

RODRIGUES, C. Os deputados assistentes sociais na Assembleia Nacional e na Assembleia da República: principais intervenções parlamentares entre 1949 e 2011. Dissertação (Mestrado em Serviço Social, Instituto Superior Miguel Torga, 2014.

ROSA, T. O associativismo das assistentes sociais no pré-25 de abril. In: MARTINS, A.; HENRÍQUEZ, B. A. (Org.). Serviço Social no feminino. Lisboa: Centro Português de Investigação em História e Trabalho Social, 1997.

ROSAS, F. Portugal século XX (1890-1976). Pensamento e acção política. Lisboa: Editorial Notícias, 2004.

. Salazar e o poder. A arte de saber durar. Lisboa: Edições Tinta da China, 2012.

SNPSS. SINDICATO NACIONAL DOS PROFISSIONAIS DE SERVIÇO SOCIAL. Parecer do SNPSS sobre o projecto do sistema escolar no que se refere ao Serviço Social, 1971.

VARELA, R. História do povo na revolução portuguesa 1974-75. Lisboa: Bertrand Editora, 2014.

ZENHA, F. et al. O caso da Capela do Rato no Supremo Tribunal Administrativo. Porto: Afrontamento, 1973.

DOI: 10.12957/rep.2017.32722

Recebido em 01 de setembro de 2017.

Aprovado para publicação em 08 de novembro de 2017.

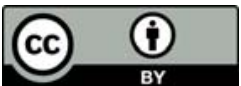

A Revista Em Pauta: Teoria Social e Realidade Contemporânea está licenciada com uma Licença Creative Commons Atribuição 4.0 Internacional. 